\title{
Diálogos e tensões da poesia experimental brasileira: poesia concreta, poema processo e cia.
}

Rogério Barbosa da Silva* I CEFET-MG

\begin{abstract}
Resumo: Hoje, já decorridos 50 anos da odisséia dos últimos grandes movimentos internacionais de vanguarda (a Poesia Concreta surgiu oficialmente em 1956), qualquer avaliação que deseja obter uma real dimensão de sua extensão e profundidade na esfera da arte deve considerar não só os tentáculos de sua expansão como também as principais tensões e divergências intrínsecas a seus projetos estéticoideológicos.

Palavras-chave: Poesia Concreta, Neoconcretismo, Tendência, Vereda.
\end{abstract}

Surgida, oficialmente, em 1956, a Poesia Concreta foi desde logo um marco nas vanguardas literárias nacionais e internacionais. Esta afirmação, muitas vezes feita pelos poetas de Noigandres e tantas vezes subestimada pela crítica brasileira, agora desvestida da polêmica, pode ser realmente tema de uma reflexão e efetivamente redimensionada. De fato, hoje, já decorridos 50 anos da odisséia dos últimos grandes movimentos internacionais de

* Doutor em Literatura Comparada (UFMG), Professor do CEFET-MG. 
vanguarda, qualquer avaliação que deseje obter uma real dimensão de sua extensão e profundidade na esfera da arte, em especial da arte literária, deve considerar não só os tentáculos de sua expansão, como também as principais tensões e divergências intrínsecas aos seus projetos estético-ideológicos.

Essas tensões e divergências seriam também decorrentes do modo como cada vanguarda atualiza e aprofunda uma vertente criativa do passado. Assim, por exemplo, no Brasil, Gilberto Mendonça Teles situa o experimentalismo de vanguarda em duas vertentes, uma que seria decorrente do próprio processo evolutivo do modernismo, e outra que a ele se opõe. Seria uma vanguarda artificial (provocada), saída do modernismo e a ele contraposta (portanto, também provocante). A "sinfonia experimental", ainda segundo Teles, se organiza em dois momentos: um que vai de 1956 a 1964 e outro que vem de 1967 aos nossos dias:

Em ambos se percebem: a onda de ascensão da maré experimentalista (a poesia concreta e o Poema-Processo) e seu refluxo natural da vanguarda modernista (Neoconcretismo, Violão de rua, Práxis, etc.). O primeiro movimento, na verdade, muito mais importante que o segundo, deixando teorias poéticas e críticas que se incorporaram à poesia e à crítica brasileiras. O segundo, de que se salvou apenas a poesia práxis, principalmente por causa da obra de seu fundador, Mário Chamie, é nitidamente conseqüência do primeiro, com repercussão mais provinciana que metropolitana constituído que é pelos epígonos e aderentes incapazes de levar adiante o mesmo afã experimentalista. (TELES, 1985, p. 399-400).

Essa observação de Gilberto Mendonça Teles é correta, considerando-se que a poesia concreta e o poema-processo inauguram novos procedimentos na cena literária brasileira. O poema concreto incorpora os dados novos da espacialização, do grafema, da tipografia em cores, do princípio de composição matemática, promovendo uma atualização crítica e material que renova o contexto nacional e projeta a poesia brasileira para um cenário internacional. Por sua vez, o Poema-Processo retoma e radicaliza procedimentos utilizados pela Poesia Concreta, respectivamente, ao enfatizar os aspectos plásticos e estruturais do poema, e ao retirar a primazia da palavra na criação poética. O Poema-Processo constrói uma poética de criação de formas que se movimentam como numa seqüência de fotogramas. É a idéia de "uma relação icônica que se estabelece entre o leitor e a percepção da 
forma cotidianamente consumida", conforme mostra Antônio Sérgio Mendonça, que aponta também como características do Poema-Processo:

[o] rompimento dos limites do espaço enquanto sobredeterminado à palavra; e finalmente vai-se buscar um dado essencial aos dois prismas do significante, busca-se ser a anti-ideologia enquanto dado verbalista. E se assinala um dado cultural importante, a poesia não é uma comunicação morta, nem reacionária, ela subsiste como tradutora de um mundo, mesmo que, hipoteticamente, não se expresse mais fundamentalmente por palavras. (MENDONÇA, 1970, p. 5).

Praxis, referida na citação acima, foi idealizada e liderada por Mário Chamie, que produziu uma teoria organizada que dá consistência à poesia produzida por um grupo de poetas não subordinados programaticamente ao movimento, mas com afinidades teórico-criativas. A base teórica são os dois volumes de Instauração Praxis, organizados por Chamie. Ao ler esses volumes, percebemos haver igualmente um esforço de clarividência do autor em propor uma nova teoria do texto e uma preocupação permanente de distinguir a sua teoria daquela proposta pela Poesia Concreta - às vezes com ataques mordazes ao grupo Noigandres. Afinal, são duas correntes paulistas se digladiando. Isso, talvez, explique a descentralização do poema-processo preposta por Wlademir Dias-Pino. Segundo o poeta, "evitou-se a penetração (do movimento) em São Paulo pelo exemplo histórico da apropriação centralizadora que sua força econômica demonstra no modernismo e na geração de 45" (DIAS-PINO, apud MENEZES, 1991, p. 83).

O objetivo de Praxis, porém, é a constituição de uma poesia que leve em conta uma "realidade situada", como demonstra o seu "Manifesto Didático", levando em conta: a) o ato de compor; b) a área de levantamento da composição; c) o ato de consumir. (CHAMIE, 1974, p. 21). O destaque a esses elementos demonstra idêntica preocupação com o processo de composição, característica também de outras correntes de vanguarda. Praxis concebe tais procedimentos enquanto resultado de um projeto correlacionado ao problema do levantamento dos dados de uma realidade existente - e não prévia. A partir dessa realidade, o poeta pesquisa o vocabulário de criação coletivo - e não pessoal -, que resulta numa articulação semântico-pragmática operada pelo autor e pelo leitor. O poema de Praxis pressupõe, no próprio gesto de criação, o leitor ativo ou participante, que interfere crítica e criativamente no texto. Com isso, o poeta de Praxis estabelece equivalência entre o ato de criar e o de consumir, conforme explica Chamie: 
O autor praxis, porém, não vai apenas do vocabulário à sintaxe. Para entrosar-se criticamente com a dialética interna da área e acionar os seus fatores de transformação, ele põe em prática a relação dos signos (levantados e articulados numa sintaxe) com o contexto geral em que a área se situa. (...) se eu parti de algo que pertence a todos e não a mim; de algo que é mais coletivo que individual. Significa mais: que eu incorporei um ato coletivo no meu ato de compor. Ora, se é assim, nada mais legítimo que um texto práxis se abra à interferência do leitor que assume a condição de co-autor. (...) O leitor se introduz nele, o redimensiona em seus significados pelo simples relacionamento que venha a estabelecer entre as palavras ou signos de conexão e a sua percepção de leitor. (CHAMIE, 1974, p. 248-249).

Evidentemente, a língua é um patrimônio coletivo, de modo que o vocabulário, por mais particularizante que seja, é parte deste patrimônio. Mas é perceptível o desejo do poeta de controlar o estilo e o próprio processo de subjetivação, em prol de uma autoria coletiva. Chamie luta pela construção de uma teoria de vanguarda autóctone, nacional, em oposição às correntes da poesia experimental em pleno vigor teórico naquele instante, como a Poesia Concreta, o Neoconcretismo e a do grupo mineiro da revista Tendência. Como se vê, é nítida a preocupação do autor de Praxis com os problemas decorrentes da industrialização, do crescimento urbano e da expropriação do trabalho, além da conseqüente luta pelo acesso das camadas populares a melhores condições de vida e às novas tecnologias; uma realidade que ela comunga com as outras vanguardas. Curiosa é a opção de Chamie, que prefere entrincheirar-se na realidade interna, para daí resolver os problemas do subdesenvolvimento nacional. Isto é, ele não percebe que, sem vincular essas discussões a um plano mundial, sua visão do problema será limitada ou parcial. O projeto estético de Praxis tem, entretanto, correspondência com a de outras correntes do experimentalismo. No plano textual, por exemplo, a preocupação com o trabalho semântico do texto aproxima-a tanto do concretismo quanto do trabalho de Affonso Ávila, um dos articuladores do grupo em torno da revista Tendência. A diferença clara em relação ao concretismo está no campo da sintaxe, pois o grupo Noigandres busca uma sintaxe analógica, paratática, justamente para romper com o discursivismo. Praxis e os escritores de Tendência exploram ainda as relações lógicas da linguagem verbal, embora os seus textos já marquem uma ruptura com o verso tradicional e procurem ir muito além da estrutura lógico-discursiva. Também é notório o empenho 
de Práxis e Tendência em construir uma literatura em compasso com os problemas imediatos da realidade nacional, o que marca diferença em relação ao grupo Noigandres. A Poesia Concreta estava muito mais concentrada na projeção de uma poesia transnacional, a partir da qual pudesse refletir sobre os problemas locais.

Esta preocupação irá aguçar o diálogo, a ruptura, e a mudança de rota entre as principais correntes de poesia experimental no país no fim da década de 60. A busca de um nacionalismo crítico vigorou até 1964, quando o golpe militar impôs novos rumos na trajetória pessoal desses poetas. Esse período marca, também, o refluxo à maré modernista, referido por Gilberto Mendonça Teles, mas, além disso, assistimos a uma guinada de muitos desses poetas a um projeto individual, numa aventura de criação inventiva e de redescoberta de linhagens e tradições. Como afirmou António Sérgio Bueno, ao lembrar a pertinência de uma reflexão sobre esse período histórico da poesia de vanguarda, já decorridos 30 anos, nos anos 60, "não havia espaço para pensamentos desinteressados". Tal consideração é relevante, pois os cenários dos anos sessenta e noventa nos trazem questões muito distintas e, de certa forma, até mesmo antitéticas, já que houve nesta última década do século Vinte uma derrocada das propostas utópicas. Mas os depoimentos dos principais atores da Semana Nacional de Vanguarda nos mostram que houve uma coerência no caminho trilhado por cada um dos poetas, em sua produção individual, se considerarmos as propostas abraçadas pelos mesmos nas várias vertentes do experimentalismo brasileiro.

Assim, por exemplo, as reflexões de Haroldo de Campos em sua conferência, por ocasião das Comemorações dos 30 Anos da Semana Nacional de Poesia de Vanguarda, não destoa, apesar dos anos decorridos, de seu compromisso com a invenção e com a ação crítica sobre a linguagem e sobre a realidade brasileira. Contrapostos os depoimentos e as obras dos participantes (na perspectiva da década de 1990), aos documentos do encontro de 1963, verificamos que houve mudanças de rumos e transformações formais, mas manteve-se no horizonte crítico e criativo dos poetas essa preocupação com a poesia de invenção e seu poder de refletir sobre problemas da realidade brasileira. No encontro de 1963, estiveram presentes muitos poetas, mas assinaram o referido documento os do grupo Noigandres, os mineiros de Tendência e Vereda, além de outros poetas como Roberto Pontual, Pedro Xisto, Paulo Leminski, Frederico Morais e intelectuais como Benedito Nunes, Luís Costa Lima, Fábio Lucas, entre outros. É, de certo modo, a sagração do "salto participante" iniciado no Congresso de Escritores em Assis no ano de 1961 - dois anos antes, portanto. Em 
síntese, o documento assinado em Belo Horizonte sistematiza objetivamente quatro aspectos da "vanguarda participante": a) consciência da forma; b) comunicação e participação; c) função prática; d) opção.

$\mathrm{Na}$ prática, buscava-se a efetivação de contatos permanentes e atuação conjunta, ou mesmo individual, nas questões da realidade nacional, além da criação de "novos métodos e meios de aplicação do texto - falado, musicado, escrito ou visualizado - além da intensificação do emprego dos já existentes (jornais, revistas, livros, cartazes, conferências, debates, gravações, rádio, televisão, cinema, teatro"). Era uma tentativa de manter o poeta situado perante a linguagem e as questões de sua época. Sem perder a dimensão lúdica da criação poética, propor uma poesia participante. Neste sentido, a obra poética e crítica de Affonso Ávila é um testemunho desta possibilidade, pois manteve sempre um trabalho atento e arguto em torno da criação poética e da investigação da tradição inventiva brasileira. Tendo elaborado o conceito de "poesia referencial" para explicar a sua produção do início dos anos 60, em especial Carta do solo, o poeta pôde fundamentar um projeto que balizou toda sua produção desde então. Com "poesia referencial", ele quer dizer: "ela é referencial por ser uma criação, uma fundação, uma invenção. E o homem só cria, só funda, inventa suas evidências numa projeção da realidade, em formas de percepção que se condicionam ao seu mundo existencial." (ÁVILA, 1978, p. 127).

Mais do que as correntes do experimentalismo referidas acima, a Poesia Concreta pagou um preço alto à crítica brasileira por ter afirmado sua condição de novidade e por se propor como uma poesia de exportação, tal como também desejou Oswald de Andrade. Alguns críticos chegaram a ver os poetas de Noigandres como epígonos de Eugene Gomringer, o que é uma grande injustiça, resultante do desconhecimento. Mais produtivo será estudála não só a partir dos seus embates dentro e fora do país, mas principalmente pelo significado que o diálogo trouxe para o campo da criação poética brasileira. Assim, é um fato que o que se entende conceitualmente como "poesia concreta" surgiu do diálogo. Usada, primeiramente, por Augusto de Campos, a designação "Poesia Concreta" foi adotada por Eugen Gomringer, conforme documenta carta a Décio Pignatari, incluída no volume Teoria da poesia concreta, em razão de uma proposta de criação de um movimento internacional de poesia concreta. Gomringer chegou à poesia concreta por via da "arte concreta" e pelo desejo de interferir livremente no arranjo visual e sonoro da escrita, conforme já 
praticava Arno Holz. Desse modo, percebe-se que os brasileiros encontraram fora do Brasil aqueles poetas cujo trabalho era afim ao que vinham produzindo desde o início dos anos 50, e lograram, isso sim, despertar uma consciência coletiva dos poetas a partir das propostas da poesia concreta no Brasil e na Europa, aproximando outras vertentes do experimentalismo.

Marlene Holzhauzen, ao estudar o diálogo entre os brasileiros e o poeta suíço-boliviano, destaca o papel de abertura estética e de liberdade adquirido pela poesia concreta. Ela mostra a importância que Gomringer assumirá na Europa, quando descreve a situação de acomodação vivenciada pela literatura alemã no início dos anos 50, momento em que uma geração de jovens escritores alemães conhecem as "Konstellationen constellations constelaciones" de Gomringer:

Para uma ala jovem de escritores alemães, a técnica que o poeta suíçoboliviano utiliza para a estruturação destes poemas, assim como o resultado obtido, revelam um "Akt der Befreiung" (ato de libertação), um vôo libertador tanto do escritor quanto da palavra, como a tende na época, o crítico e poeta alemão Helmut Heissenbüttel (In: Gomringer, 1969, p. 13), descerrando uma outra perspectiva de atuação para os jovens poetas da República Federal da Alemanha. (HOLZHAUSEN, 1996, p. 108).

Lendo os manifestos publicados por Gomringer e os textos teóricos escritos pelos brasileiros, observamos a grande afinidade entre as idéias dos autores, como, por exemplo, a valorização da palavra explorada tipográfica e espacialmente, refletindo a preocupação de não se restringir ao verbal. Essa é uma característica marcante do primeiro momento da Poesia Concreta, mas ainda é fundamental na produção poética de Gomringer, assim como na de Haroldo de Campos. É também um primeiro passo para o desenvolvimento de uma poesia intersemiótica, momento em que poetas como Augusto de Campos, Décio Pignatari e outros passam a entrelaçar o código verbal e o não-verbal. Já no manifesto "Concrete Poetry", de 1956, Gomringer opõe a Poesia Concreta à poesia tradicional corrente, distinguindo-a em três aspectos: o aspecto visual, os elementos de informação e de comunicação e o caráter internacional. O primeiro aspecto trata, obviamente, da substituição do verso linear por uma configuração estrutural e espacial do poema, em que sua forma visível seja idêntica à de sua estrutura. O segundo aspecto está relacionado à problemática da comunicação no poema concreto, já que as informações estéticas do poema são reveladas por sua configuração estrutural, 
isto é, em sua forma concisa e não velada de linguagem. Com relação ao terceiro aspecto, Gomringer justifica a sua crença de que a Poesia Concreta poderia realizar a idéia de uma "poesia universal", em virtude do poliglotismo que toma os poetas afinados com o movimento:

Este poliglotismo intencional poderá permitir que algumas línguas vivas entrem em contato uma com a outra, como numa festa, por exemplo, ou em um vôo, onde pessoas de diferentes experiências, habilidades, idiomas e aparências externas podem ser observadas. Então nós também levamos em conta a poesia moderna de dialeto, que sabe que o mesmo representa o arquivo lingüístico fora do qual podem ser ganhas formas individuais e experiência lingüística fundamental. (Apud SOLT, 1970, p, 68)

Essa idéia de uma poesia que converge para uma linguagem universal não aparece evidenciada na teoria da Poesia Concreta brasileira. Em suas produções poéticas, há, entretanto, inúmeros exemplos de poemas que exploram palavras de outros idiomas, as quais, em razão da articulação imagética, semântica, sonora e das possibilidades de combinação e de arranjo, alcançam maior rendimento expressivo e exploração do código verbal como a linguagem que ele é (não como língua nacional). A título de exemplo, citamos os trabalhos dos brasileiros Augusto de Campos (com a série "equivocábulos"), Décio Pignatari (LIFE e os ideogramas verbais), Pedro Xisto, dos poetas de Poema-Processo, que não se restringem a uma língua e muito menos a um único código. Importa neste caso que a língua escolhida seja dúctil ao projeto proposto e, sem necessitar de uma tradução, o poema seja capaz de mexer com a medula da linguagem. Basta lembrar poemas "hombre/ hembra/hambre" ou "Homem/Woman", de Pignatari, em que o poeta explora o potencial ideogramático ou sonoro das palavras para jogar com os idiomas.

Embora não seja possível aprofundar as discussões que as várias correntes da poesia experimental encetaram, muitas vezes impulsionadas pela poesia concreta, é importante assinalar que, decorridos 50 anos, o trabalho realizado pelos poetas paulistas em consonância com poetas de outras vertentes mudou toda a discussão em torno da poesia brasileira. Há que se fazer ainda um balanço acerca de todas as contribuições que a poesia concreta brasileira deu às vanguardas internacionais e o que delas recebeu. Mas efetivamente ela se tornou uma referência observável em vários continentes, onde muitas vezes os poetas paulistas tiveram seus trabalhos expostos ou publicados em antologias, etc. Eles se inseriam num "turbilhão cultural" que varreu o mundo a partir dos anos sessenta. Hoje, 
efetivamente, importa muito mais a leitura do projeto consistente que cada um dos poetas, individualmente, desenvolveu em sua obra. Mas a avaliação crítica do movimento será sempre importante como forma de entendermos a formação do leitor diante de obras tão abertas e tão abstratas que lhe são oferecidas pelas formas contemporâneas do experimentalismo.

Abstract: Today, 50 years after the odissey of the last great international avant-garde movements (Brazilian Concrete Poetry was officially launched in 1956), any evaluation aiming to appraise the real measures of their extension and depth in the sphere of art, in special of literary art, must take into consideration not only the tentacles of their spreading move but also the main tensions and divergences intrinsic to their aesthetic-ideological agendas.

Key words: concrete poetry, neo-concretism, Tendência, Vereda.

$$
\text { Referências Bibliográficas }
$$

ÁVILA, Affonso. Opoeta e a consciência crítica. São Paulo: Summus Editorial, 1978.

BUENO, Antônio Sérgio. Semana Nacional de Poesia de Vanguarda - 30 anos. Belo Horizonte: Prefeitura Municipal de Belo Horizonte, 1993, p. 9-14. (Catálogo da Exposição Semana Nacional de poesia de Vanguarda).

CAMPOS, Augusto et al. Teoria da poesia concreta. São Paulo: Livraria Duas Cidades, 1975.

CAMPOS, Haroldo. Reflexões após um trintênio. In: SANTA ROSA, Eleonora (Coord.). 30 anos da Semana Nacional da Poesia de Vanguarda - 1963/93. Belo Horizonte: Prefeitura Municipal de Belo Horizonte: Secretaria Municipal de Cultura, 1993. p.36-45.

CHAMIE, Mário. Instauração Práxis. São Paulo: Quíron, 1974. 2v.

HOlZHAUSEN, Marlene. Poesia concreta: dois percursos, um diálogo. 1996. Tese (Doutoramento em Literatura Alemã) - USP, São Paulo. (mimeo).

MENDONÇA, Antônio Sérgio. Poesia de vanguarda no Brasil. Rio de Janeiro: Vozes, 1970 .

MENEZES, Philadelpho. Poética e visualidade - uma trajetória da poesia brasileira contemporânea. São Paulo: Perspectiva, 1991.

SOLT, Mary Ellen (ed., introd.). Concrete poetry: a world view. Bloomington: Indiana Univesity Press, 1970. 